\title{
Morphological and Morphometric Studies of the Gas- tro-intestinal Tract of the Guinea Pig (Cavia porcellus - Linnaeus, 1758)
}

\author{
${ }^{* 1}$ Imam, J., ${ }^{1}$ Hambolu, J.O., ${ }^{1}$ Onyeanusi, B.I., ${ }^{2}$ Ayo, J.O. and \\ 'Sulaiman, M. H. \\ ${ }^{1}$ Department of Veterinary Anatomy, Ahmadu Bello University, Zaria-Nigeria \\ 2 Department of Veterinary Physiology, Ahmadu Bello University, Zaria-Nigeria \\ ${ }^{*}$ Correspondence author: Dr. Imam, J.
}

With 8 figs, 1 table

\section{Abstract}

The investigation of gross anatomical features of the gastro - intestinal tract (GIT) of the guinea pig (Cavia porcellus, Linnaeu-1758) was carried out. The aim of the study was to describe the gross anatomical anatomical features of the gastro - intestinal tract (GIT) of the guinea pig (Cavia porcellus, Linnaeus-1758). Fifteen healthy adult guinea pigs of both sexes were purchased from Samaru market in $\mathrm{Za}$ ria. The animals were anaesthetized and sacrificed, with the oesophagus, tongue, stomach, small and large intestines, liver, and gall bladder dissected. The tissue samples were immediately fixed by complete immersion in $10 \%$ normal formalin, labeled and fixed. The various segments of the GIT were weighed, measured and photographs were taken. The results of the morphologic studies showed that the oesophagus was a direct continuation of the pharynx, extending from the pharynx to the cardia of the stomach. The oesophagus lay dorsal to the trachea throughout its length until it entered the stomach. The stomach showed three regions, namely; cardia, fundus and pylorus, while the small intestine showed also three regions, namely; the duodenum, the jejunum and the ileum. The large intestine had three distinct regions; the caecum, the colon and the rectum. The liver was divided into four lobes, namely: the right, the left, the intermediate and the accessory lobes. The gall bladder was observed as a sac-like structure, with a light yellowish green colouration. The tongue was observed as a mass of striated muscle fibers covered by a mucous membrane. This work concluded that the gastrointestinal tract of guinea pig was similar to those of other rodents.

Keywords: Anatomical features, gastrointestinal tract, Gross anatomy, Guinea pig 


\section{Introduction}

Guinea pig is a mammalian member which belongs to the order Rodentia, suborder Hystricomorpha, Family Caviinae (Jaffe, 2009). It's characterized by a large head, short legs, unfurred, short ears, no external tail, two large pairs of chisel like incisors and three to five molars, four digits on the forepaw and three on the hind foot (Wikipedia, 2008). Guinea pigs have long been recognized as representatives of laboratory animals (Harkness \& Wargner, 1993). The first experimental use of this species was reported by Lavoisier in 1790, in investigations of the effects of heating in the guinea pig (Andrade et al., 2006). Thereafter, the animals had been largely used as experimental models in several areas of biology (Karol, 1994). The animals were frequently used as model organisms in the $19^{\text {th }}$ and $20^{\text {th }}$ centuries, resulting in the epithet "guinea pig" for a test subject, but have since been largely replaced by other rodents such as mice and rats. Guinea pigs are still used in research, primarily as models for human medical conditions such as juvenile diabetes, tuberculosis, scurvy, and pregnancy complications (Fitzpatrick \& Keegan, 2007). The science-oriented studies of anatomy and physiology constitute the basis for the interpretation of imaging studies as well as for the success of clinical and surgical procedures (Peixoto et al., 2010). The morphology of the gastro-intestinal tract (GIT) has been reported in different species of animals such as the birds (Devyn et al., 2000), African Giant Rat (Nzalak, 2010), grasscutter; and (Kelvin, 2016). Macroscopic and histological studies of the gastro-intestinal tract of the grasscutter have been done (Byanet et al., 2008). Gross anatomical aspects of the gastro- intestinal tract of the wild African giant pouched rat has been documented (Ali et al., 2008). As far as we are aware, no work was done on the gastro-intestinal tract of the guinea pig in this part of the country.

An understanding of the animal's adaptation to diet and habit is essential for the proper care of domesticated animals and preservation of endangered species (Finegan \& Steven, 2008). The vertebrate digestive system demonstrates a wide structural and functional varieties (Finegan \& Steven, 2008). The study may be useful in the understanding of the feeding patterns. This will give an insight into the efficacy of the gastro-intestinal tract in the guinea pig. The knowledge of which may be used in breeding programmes, or as animal models, feed formulation and nutrient trials. Therefore, the gross anatomical studies of the gastro - intestinal tract of the guinea pig is poorly understood and needs further investigation. The general aim of the study was to describe the gross anatomical features of the gastrointestinal tract of the guinea pig. 


\section{Materials and Methods}

\section{Study area}

The experiment was carried out in the Department of Veterinary Anatomy, Faculty of Veterinary Medicine, Ahmadu Bello University, Zaria $\left(11^{\circ} 04 \mathrm{~N}\right.$, $7^{0} 42^{1} \mathrm{~N}$ ), located in the Northern Guinea Savannah zone of Nigeria. Zaria has an estimated land area of about 300 square kilometers, and it is approximated that about $40-75 \%$ of its working population derive its means of livelihood from agriculture (Ahmadu Bello University, 2000; Anonymous, 2013).

\section{Ethical approval}

Ethical approval was obtained from the Committee on Animal Use and Care (CAUC) of Ahmadu Bello University, Zaria with approval number, ABUCAUC/2017/032. This was to ensure that animals were humanely handled (AVMA, 2013).

\section{Experimental animals}

Fifteen healthy adult guinea pigs (Cavia porcellus) weighing between 250-300 g of both sexes were purchased from Samaru market in Zaria, Nigeria. They were transferred in standard laboratory cages to the Department of Veterinary Anatomy, Faculty of Veterinary Medicine, Ahmadu Bello University, Zaria, where the experiment was performed. The animals were acclimatized for two weeks before the commencement of the experiment, during which they were given access to water and standard feeds ad libitum.

\section{Morphological studies}

Photograph of the live guinea pig was taken before the sacrifice, according to Adeyemo and Oke (1990) and Nzalak, (2010). The buccal cavity of each guinea pig was opened after sacrifice, and the tongue was pulled to the side to expose the teeth. The same experimental animal was placed on a lateral recumbency, while the skin and fascia at the base of the ear and the caudal border of the mandible were removed. The parotid and mandibular salivary glands were dissected out. Incision was made from the first cervical vertebra up to the level of the pelvic region to show the various portions of the GIT in situ. The portions were exteriorized and stretched out to full length. The positions of pancreas, gall bladder and lobes of the liver were recorded. . The tissue samples were immediately fixed by complete immersion in $10 \%$ normal formalin, labeled and fixed Photographs of the relevant structures were taken.

\section{Results}

\section{The oesophagus}

The oesophagus was observed grossly as a direct continuation of the pharynx, extending from the pharynx to the cardia of the stomach. The oesophagus lay dorsal to the trachea throughout its length (Fig 1) until it entered the stomach (Figs 5, 6).

\section{The stomach}

Gross observation of the stomach showed that it occupied the upper left 
portion of the abdominal cavity, largely concealed by the liver from view (Figs $1,2,3)$. The stomach appeared homogenous and pinkish in colour externally. It was subdivided into three areas: cardia, fundus and pylorus. There was a cardiac portion surrounding the oesophagus, a fundus that ballooned upward, and to the left a body that accounted for most of the stomach mass, and a funnel-shaped terminal pylorus, terminating in the duodenum at the pyloric sphincter (Fig 6).

\section{The small intestine}

The gross examination of the small intestine had three regions: duodenum, jejunum and ileum. The duodenum was in contact with the pyloric region of the stomach proximally (gastro-duodenal junction) and continued with the jejunum distally, while the jejunum continued with ileum distally. The ileum was observed to terminate where it joined the caecum at the ileo-caecal junction (Figs 3, 7).

\section{The large intestine}

The large intestine revealed three distinct regions: caecum, colon and rectum. The caecum was observed to be prominent and dilated, thin-walled with taenia coli, running in three thin bands along the entire length, causing outpouching or haustra of the intervening wall. The rectum was observed to look like the colon, but is shorter and medially located in the pelvic girdle (Figs 3 , 7).

\section{The liver}

Morphological examination of the liver showed that it was located caudal to the diaphragm in the superior medial aspect of the abdominal cavity. It has two surfaces: the diaphragmatic surface and the visceral surface. The diaphragmatic surface was convex while the visceral surface was concave. The visceral surface had impression of the stomach. The liver was observed to be dark-brown in colour with smooth and glossy surface throughout. The liver was found to be divided into four lobes namely, the right, the left, the intermediate and the accessory lobes $(2,4)$.

\section{The gallbladder}

The gallbladder was embedded in the visceral surface of the liver and it was sac-like organ, with a light yellowishgreen colouration. Its surface was soft and smooth to touch (Fig 4).

\section{The tongue}

On gross observation, the tongue appeared as a mass of striated muscle, covered by a mucous membrane. It lied on the floor of the oral cavity, with its rostral portion bearing a longitudinal groove (median sulcus). The tunica mucosa was lined by stratified squamous keratinized epithelium, covering the filiform and fungiform papillae (Fig 8).

\section{Morphometric studies}

The mean body weight of the guinea pigs were $211 \pm 13.88 \mathrm{~g}$, while that of 
the GIT was $44.14 \pm 2.25 \mathrm{~g}$. The mean weight of the oesophagus was $0.21 \pm$ $0.02 \mathrm{~g}$. The mean weight of the stomach was $2.75 \pm 0.48 \mathrm{~g}$. The mean weight of the small intestine and its segments were as follows: duodenum, jejunum and ileum were $6.55 \pm 0.40 \mathrm{~g}$; $1.84 \pm 0.34 \mathrm{~g} ; 3.92 \pm 0.53 \mathrm{~g}$ and $0.75 \pm$ $0.09 \mathrm{~g}$, respectively. The mean weight of the large intestine and its segments: caecum, colon and rectum were 13.84 $\pm 0.51 \mathrm{~g}, 6.54 \pm 0.18 \mathrm{~g}, 6.80 \pm 0.60 \mathrm{~g}$ and $0.50 \pm 0.05 \mathrm{~g}$, respectively (Table 1). The mean weight of the accessory GIT glands: liver, gallbladder and tongue were $9.04 \pm 0.61 \mathrm{~g}, 0.24 \pm 0.06$ $\mathrm{g}$, and $0.92 \pm 0.05 \mathrm{~g}$, respectively (Table 1).

The large intestine had the highest mean weight $(13.84 \pm 0.51 \mathrm{~g})$, followed by the small intestine $(6.56 \pm 0.40 \mathrm{~g})$ and then the stomach $(2.75 \pm 0.48 \mathrm{~g})$. The liver was found to have the highest mean weight $(9.04 \pm 0.61 \mathrm{~g})$ among the gastro-intestinal glands (Table 1 ).

\section{Discussion}

In the present study, morphologic features showed that the stomach of the guinea pig was divided into three regions; the cardiac, the fundus and the pylorus. These findings agree, with the reports of Kelvin (2016), and O'Malley (2005) who reported that the stomach of rabbit has three different regions (cardiac, fundus and pylorus). The lack of significant difference between the male and female guinea-pig stomach shows that sexual dimorphism was absent in the stomach of the guinea pig. The small intestine of the guinea pig was made up of the duodenum, jejunum and ileum, which agrees the findings of Kelvin (2016) who reported the presence of these segments in the grasscutter. A similar finding was revealed in the rabbit by Bob et al., (2012) while Ali et al., (2008); Byanet et al., (2008) and Nzalak (2010) had observed the same findings in the AGR. The large intestine of the guinea pig was observed to be made up of the caecum colon and rectum, with the caecum being larger than any other segment of the GIT. This agrees with the findings of Grant (2010). The caecum occupied most of the abdominal cavity, which agreed with the findings of Nzalak (2010); Stan et al. (2014) and Kelvin (2016) in the AGR, rabbit and grasscutter, respectively.

\section{Conclusion}

In conclusion, the gross anatomical features of the gastrointestinal tract in the guinea pig were similar generally to those of other rodents and are essential for a better understanding of the gastro -intestinal tract of the guinea pig and con-sequently, its efficient use as laboratory animal for modern anatomical studies.

\section{References}

Adeyemo, O. \& Oke, B.O. (1990): Com-parism of the testicular and epididymal proteins of the African Giant 
rat (Cricetomys gambianus) and laboratory rats. Tropical Veterinarian, 8: 1727.

Ahmadu Bello University (ABU, 2000): Zaria master plan, Department of Urban and Regional Planning, $A B U$, Zaria, Pp. 1-12.

Ali, M.N.; Byanet, O.; Salami, S.O.; Imam, J.; Maidawa, S.M.; Umosen, A.D. \& Nzalak, J.O. (2008): Gross Anatomical aspect of gastrointestinal tract of the wild African Giant Rat (Cricetomys gambianus). Journal of Scientific Research and Essay, 3 (10): $518-520$.

Andrade, A.; Pinto, S.C.; Oliveira, R.S. (2006): Animais de laboratorio: Criaca e experimentacao. Rio de Janeiro; fiocruz, pp.388.

Anonymous (2013): http://Zaria,en. Wikipedia. Org/wiki/Zaria, Retrieved at 17:00 GMT on the $14^{\text {th }}$ March, 2013.

\section{American Veterinary Medical Asso-} ciation (AVMA) (2013): Guideline for euthanasia of animals. 1931, N, Meac-ham road, Schaumburg, IL 60 173.

Bob, D.; Damian, A.; Gudea, A.; Dezdrobitu, C.; Martonos, C.; Ghiurco, F.; Irimescu, I. ; Stan, F. (2012): Compa-rative Anatomical Study of the Small Intestine in Chinchilla and Domestic Rabbit. Scientific
Works. Series C. Veterinary Medicine. Vol. LIX (3), p 6-12.

Byanet, O.; Nzalak, J.O.; Salami, S.O.; Nwaogu, I.C.; Bosha, J.A.; Umosen, A.D.; Ojo, S. A.; Obadiah, H.I. (2008): Macroscopic Studies of the gastrointestinal tract of the African Grasscutter (Thyronomys Swinderianus). Medwell Online Journal of Veterinary Research, 2 (2): 17-21.

Devyn, M.S.; Rayetta, C.; Grast, N.; Theodosio, C.J., Clifford, J.T. \& Nanette, M.N. (2000): Evolution relationship between the amphibian, avian and mammalian stomach. Evolution and Development, 2 (6): 348-359.

Finegan, E.J. and Steven, C.E. (2008): The digestive system of vertebrate, (Anatomy of the fish digestive system). University of Guelph, Ontario, N 1 G 2W1 Canada; Department of molecular biomedical sciences, College of Veterinary Medicine, North Carolina State University, Geleigh, NC, 27606 US, pp.420.

Fitzpatrick, S.M. and Keegan, W.F. (2007): "Human impacts and adaptations in the Caribbean Islands: an historical ecology approach". Earth and Environ-mental Science Transaction of the Royal Society of Edinburgh, 98: 29-45.

Grant, K. (2010): Adaptations in Herbivore Nutrition. Mammal medicine, Lafeber Vet. $7^{\text {th }}$ Retrieved August, 
2015 at 13:00 GMT from http://lafeber.com/vet/mammalmedicine ladaptationsinherbivorenutrition.

Harkness, J. and Warner, J. (1993): Biologia e clinica de coelbos e roedores. ( $3^{\text {rd }}$ Edition) Sao Paulo: Roca, pp. 238.

Jaffe, K.E. (2009): Introduction to mammal taxonomy and evolution. Sonoma State University, Pp. 1 - 100.

Karol, M.H. (1994): Animal models of occupational asthma. European Respi-ratory Journal, 7: 555-68.

Kelvin, K.B. (2016): Histological and Histochemical Studies of the Gastrointestinal Tract and Accessory Digestive glands of the Grasscutter (Thryonomys swinderianus). An MSc Thesis, Ahmadu Bello University, Zaria Kaduna- Nigeria, pp. 108.

Nzalak, J.O. (2010): Anatomical and Histochemical Studies of the Digestive System of the African Giant Rat (Cricetomys gambianus - Waterhouse).
PhD Thesis, Ahmadu Bello University, Zaria - Nigeria, Pp. 52-55.

O'Malley, B. (2005): Clinical Anatomy and Physiology of Exotic Species: Structure and Function of Mammals, Birds, Reptiles, and Amphibians. Elsevier Saunders, London, U.K. pp. 187189.

Peixoto, G.C.X; Lira, R.A.; Alves, N.D.; Silva, A.R. (2010): Bases fisicas de formacao de imagem ultrassonografica. Acta Veterinaria Brasilica, 4: 15-24.

Stan, F.; Damian, A., Gudea, A.; Dezdrobitu, C.; Bob, D.; Martonoş, C.; Bochis, I.; Pogana, B. (2014): Compa-rative Anatomical Study of the Large Intestine in Rabbit and Chinchilla. Bulletin UASVM Veterinary Medicine 71 (1), 208-212.

Wikipedia $\AA$ (2008): A registerd trademark of the foundation incorporated. A U. S. website on Africarodentia, httpi//en,Wikipedia.org/wiki/Guinea pig.

\section{Corresponding Author}

Email: jibsimam@gmail.com

¡imam@abu.edu.ng

iibsimam@yahoo.com

Phone: +2348036194202 


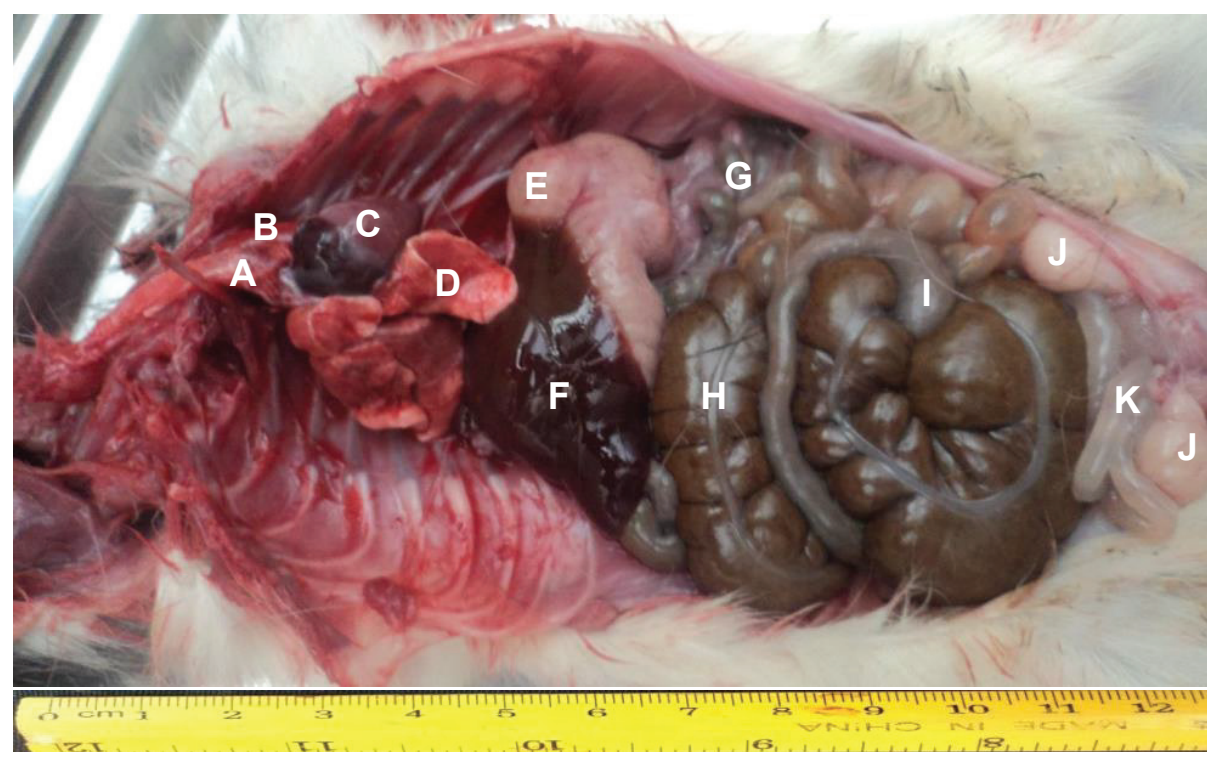

Fig (1): Thoracic and abdominal viscera in situ of the Guinea pig showing the trachea (A), the oesophagus (B), the heart (C), the lung (D), the stomach (E), the liver $(F)$, the small intestine $(G)$, the caecum

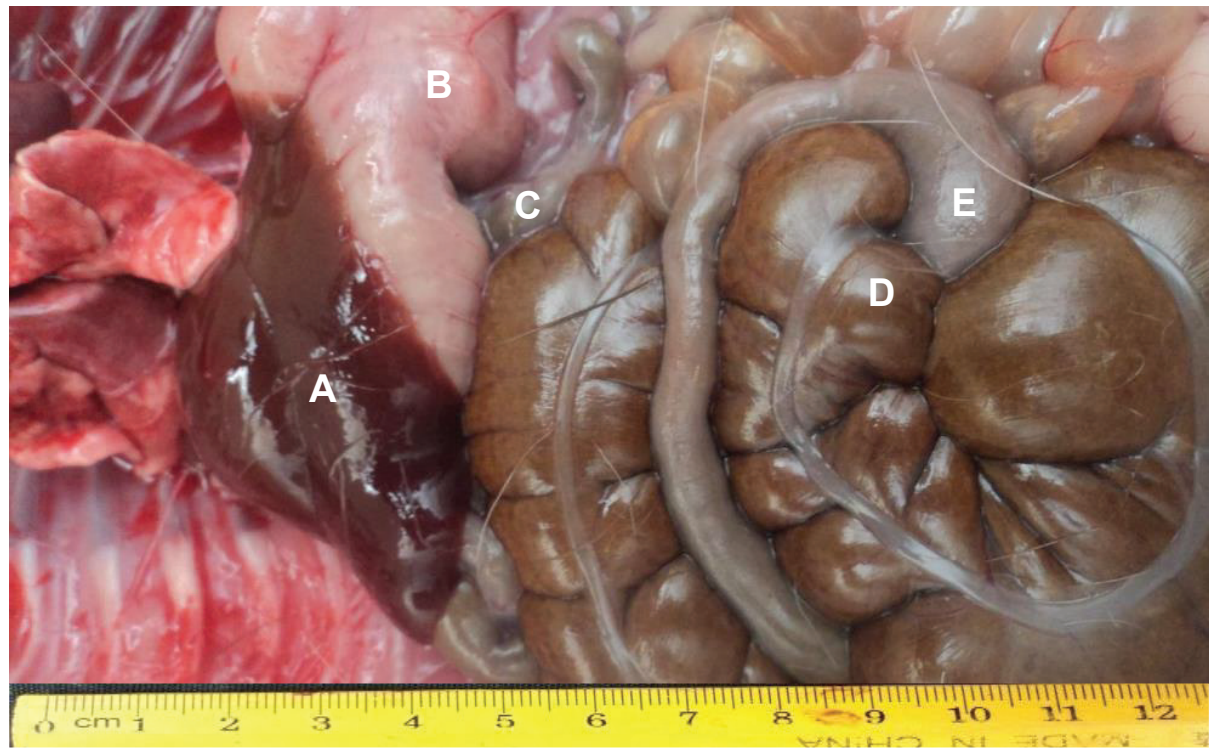

Fig (2): The structures of gastro-intestinal tract (GIT) in situ of the Guinea pig showing the liver (A), the stomach (B), the duodenum (C), the caecum (D) and the colon (E)

J. Vet. Anat. 


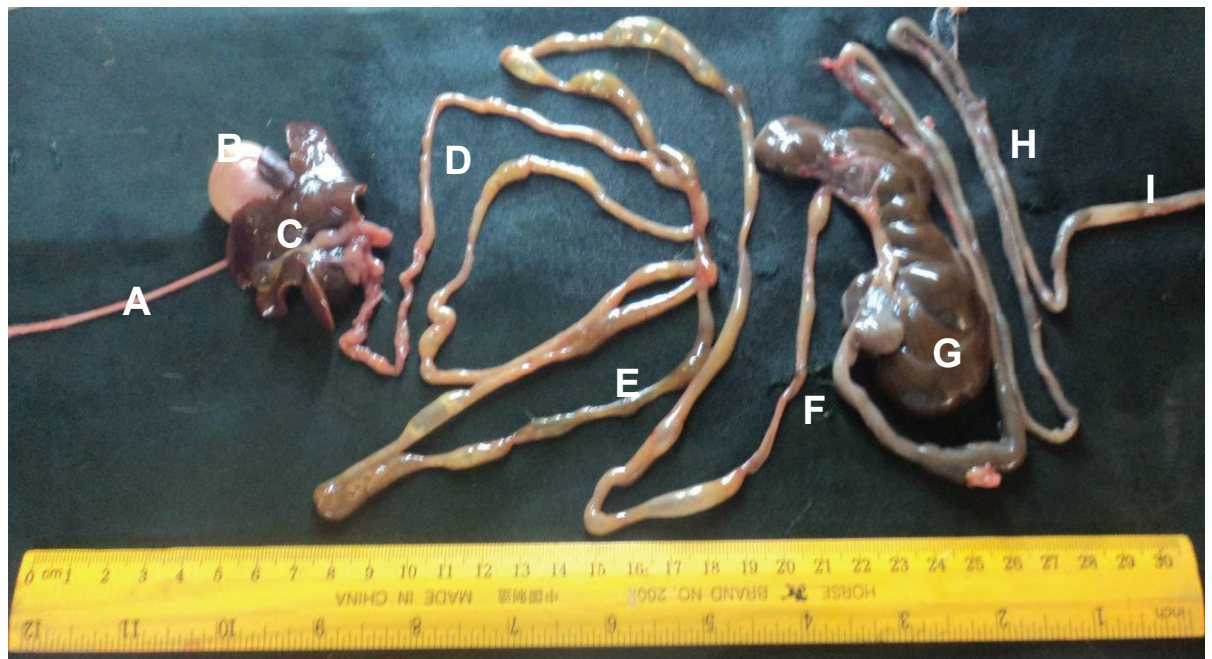

Fig (3): The structures of gastro-intestinal tract (GIT) of the Guinea pig. Note: the oesophagus (A) non-glandular stomach (B), the liver (C), the duodenum (D), the jejunum (E), the ileum (F), the caecum (G), the colon $(\mathrm{H})$ and the rectum (I)

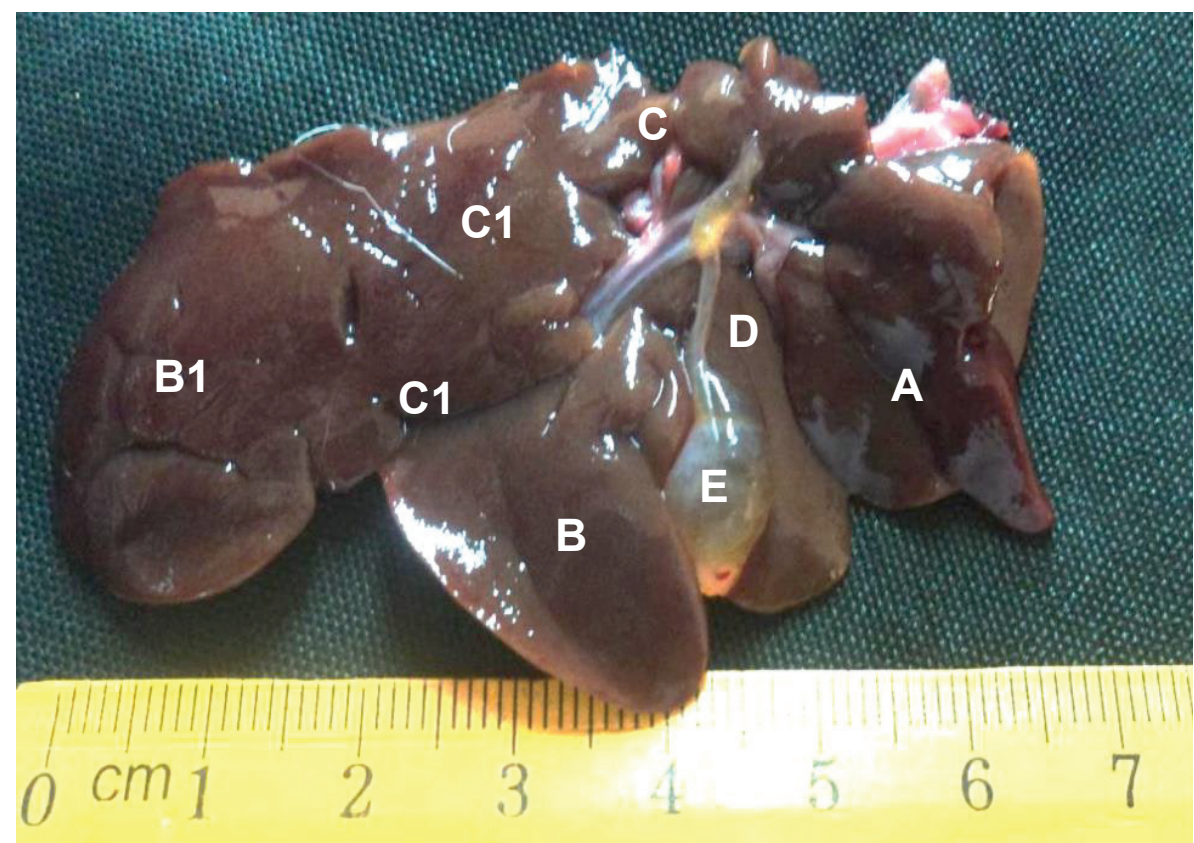

Fig (4): The Visceral surface of the liver in the Guinea pig. Note: the right lobe (A), the left lobes (B \& B1), the intermediate lobes (C \& C1), the accessory lobe (D) and gall bladder (E). 


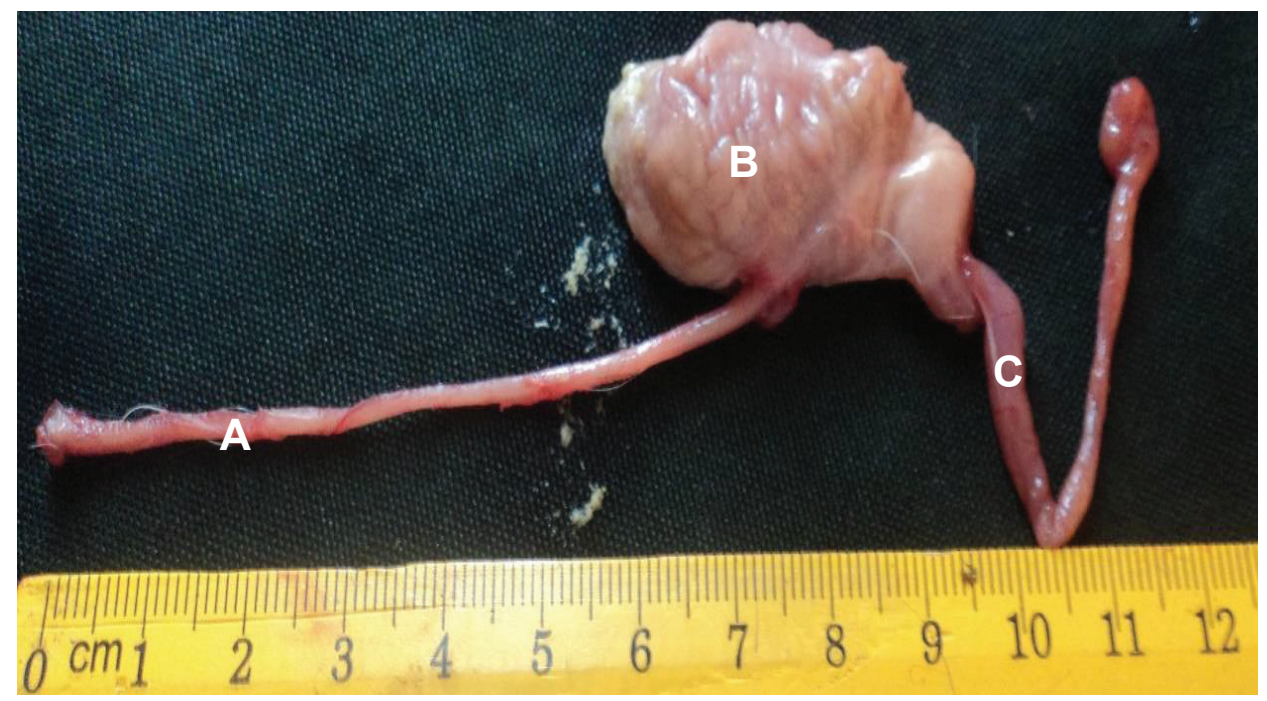

Fig (5): The gastro-intestinal tract (GIT) of the Guinea pig. Note: the oesophagus (A), non- glandular stomach (B) and the duodenum (C)



Fig (6): The Internal surface of the Guinea pig stomach. Note: the stump of the esophagus (A) and the non-glandular stomach (B)

J. Vet. Anat. 


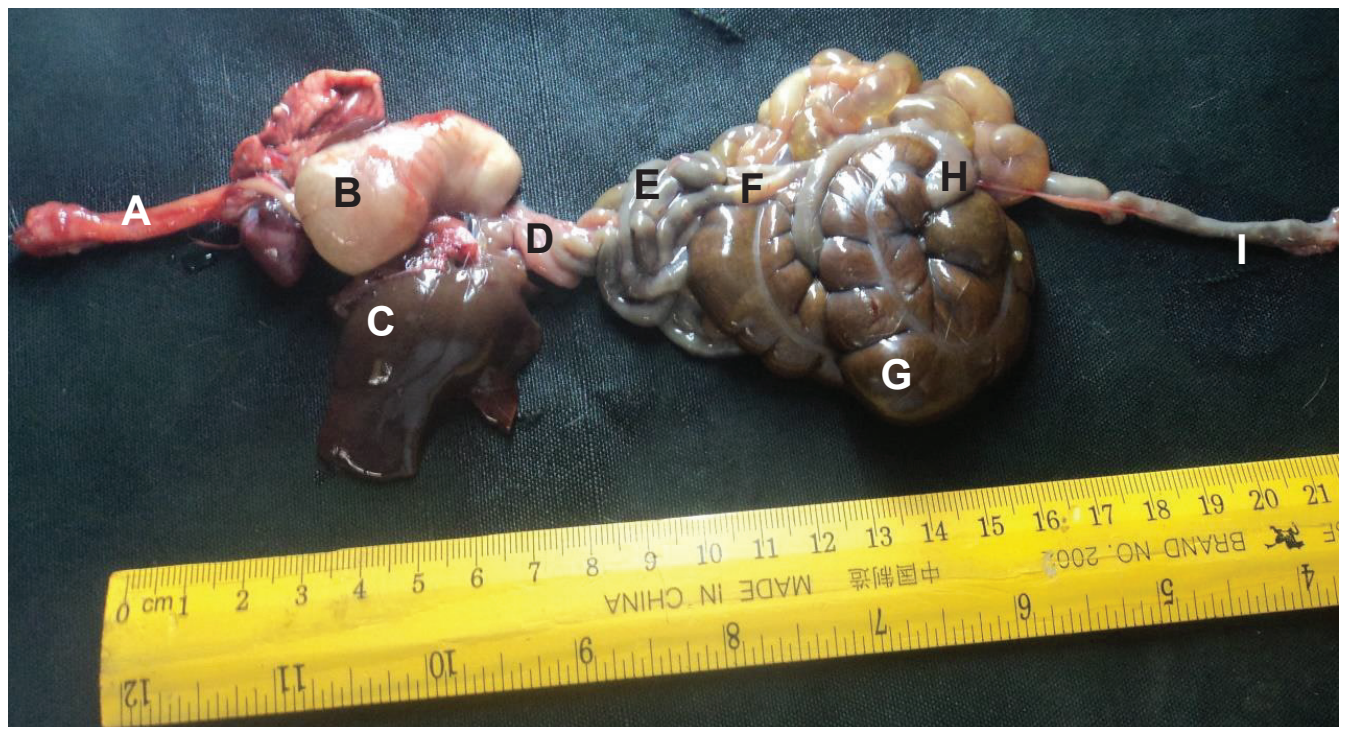

Fig (7): The gastro-intestinal tract (GIT) of the Guinea pig. Note: the oesophagus (A), the non-glandular stomach (B), the liver (C), the duodenum (D), the jejunum (E), the ileum (F), the caecum (G), the colon $(H)$ and the rectum (I)



Fig (8): Dorsal surface of the tongue in the Guinea pig. Note: the radix of the tongue (A), dorsal prominence (B) and median sulcus (C) (x 10 magnification) 
Table (1): Weight of Gastro-intestinal Tract and its Accessory Glands in the Guinea pig $(n=15)$

\begin{tabular}{lccc}
\hline Structures & Mean \pm SEM & Minimum $(\mathbf{g})$ & Maximum (g) \\
\hline Body weight & $211.5 \pm 13.88$ & 118 & 311.1 \\
Weight of GIT & $44.14 \pm 2.25$ & 24.07 & 58.26 \\
Weight of oesophagus & $0.21 \pm 0.02$ & 0.09 & 0.33 \\
Weight of stomach & $2.75 \pm 0.48$ & 0.42 & 8.10 \\
Weight of small intestine & $6.56 \pm 0.40$ & 3.60 & 9.12 \\
Weight of duodenum & $1.84 \pm 0.35$ & 0.51 & 4.53 \\
Weight of jejunum & $3.92 \pm 0.53$ & 1.12 & 7.28 \\
Weight of ileum & $0.80 \pm 0.09$ & 0.38 & 1.75 \\
Weight of large intestine & $13.83 \pm 0.51$ & 10.81 & 17.33 \\
Weight of caecum & $6.54 \pm 0.18$ & 5.30 & 7.62 \\
Weight of colon & $6.80 \pm 0.60$ & 2.84 & 10.81 \\
Weight of rectum & $0.49 \pm 0.05$ & 0.24 & 0.90 \\
Weight of tongue & $0.92 \pm 0.05$ & 0.63 & 1.29 \\
Weight of liver & $9.04 \pm 0.61$ & 5.92 & 14.28 \\
Weight of gall bladder & $0.24 \pm 0.06$ & 0.06 & 0.86 \\
\hline
\end{tabular}

SEM $=$ Standard Error of Mean 